\title{
Multivariate dynamic linear models for estimating the effect of experimental interventions in an evolutionary operations setup in dairy herds
}

\author{
Anna Helena Stygar, ${ }^{* 1}$ Mogens Agerbo Krogh, $†$ Troels Kristensen, $\ddagger$ Søren Østergaard, $\dagger$ \\ and Anders Ringgaard Kristensen* \\ *Department of Veterinary and Animal Sciences, University of Copenhagen, Grønnegårdsvej 2, DK-1870 Frederiksberg C, Denmark \\ †Department of Animal Science, and \\ łDepartment of Agroecology, Blichers Allé 20, DK-8830 Tjele, Aarhus University, Denmark
}

\begin{abstract}
Evolutionary operations is a method to exploit the association of often small changes in process variables, planned during systematic experimentation and occurring during the normal production flow, to production characteristics to find a way to alter the production process to be more efficient. The objective of this study was to construct a tool to assess the intervention effect on milk production in an evolutionary operations setup. The method used for this purpose was a dynamic linear model (DLM) with Kalman filtering. The DLM consisted of parameters describing milk yield in a herd, individual cows from a herd, and an intervention effect on a given day. The model was constructed to handle any number of cows, experimental interventions, different data sources, or presence of control groups. In this study, data from 2 commercial Danish herds were used. In herd 1, data on 98,046 and 12,133 milkings registered from an automatic milking system (AMS) were used for model building and testing, respectively. In herd 2, data on 3,689 milkings on test days were used for estimating the initial model parameters. For model testing, data from both bulk tank milk yield (85 observations) and test-day milkings $(1,471)$ were used. In herd 1 , the manager wanted to explore the possibility of reducing the amount of concentrate provided to the cows in an AMS. In herd 2, the manager wanted to know if the milk yield could be increased by elevating the energy level provided to the cows in a total mixed ration. The experiment conducted in herd 1 was designed with a treatment and a control group, whereas in herd 2 we used a pretest/posttest design. The constructed tool provided estimates (mean and confidence intervals) for each of 3 interventions carried out in both herds. In herd 1 , we concluded that the reduction in concentrate amount provided in the AMS had no nega-
\end{abstract}

Received November 3, 2016.

Accepted March 9, 2017.

${ }^{1}$ Corresponding author: as@sund.ku.dk tive influence on milk yield. For herd 2, the increased level of energy had a significant positive effect on milk yield but only for the first intervention. In this herd, the effect of intervention was also evaluated for cows in the first lactation and without bulk tank records. The presented model proved to be a flexible and dynamic tool, and it was successfully applied for systematic experimentation in dairy herds. The model can serve as a decision support tool for on-farm process optimization exploiting planned changes in process variables and the response of production characteristics.

Key words: dynamic linear model, evolutionary operation, milk yield

\section{INTRODUCTION}

Production conditions on dairy farms are not identical. Therefore, certain solutions regarding, for example, feeding, milking strategy, or management, can bring positive production results for some producers but negative results for others.

The dairy industry is not the only one that has to overcome this problem. Managers employed in the chemical and engineering industry noticed that some production strategies will not work equally well for all factories. A solution for this problem was introduction of evolutionary operations (EVOP) methods based on systematic experimentation during the production process (Box, 1957). Evolutionary operation is used for process optimization to find a way to alter production to be more efficient. The major advantages of this method are the application of statistical ideas and the ability to be run during the standard production process in the local environment.

To apply EVOP to a production process, first production characteristics to be improved (for dairy operations, e.g., milk yield, SCC) need to be identified and their current values have to be known. Second, small changes (hereafter called interventions) to the input factors, also called process variables, need to be planned and implemented. Alternatively, small changes 
in the process variables that are invoked during normal production flow on dairy farms can also be monitored and used to gain knowledge. As described by Myers and Montgomery (1995), the changes in the production variables should be relatively small, yet they should be large enough to discover potential improvements in productivity. Third, to properly evaluate the effect of interventions, data on response variables of interest need to be collected and evaluated. Moreover, to properly assess the effect of intervention on the productivity, an estimate of measurement error is required. Finally, based on observed results, the decision on implementing new production conditions (e.g., concerning feeding) should be made.

Evolutionary operation has been widely and successfully applied to the process industries (Box and Draper, 2006); however, applications of the EVOP concept in livestock sciences are rather scarce. To the best of our knowledge, no studies have demonstrated the use of EVOP in the dairy industry. Andersen et al. (2016) demonstrated how the EVOP can guide pig farmers to optimize their production. Using an EVOP framework they have shown that changes in the diurnal rhythm of water consumption can be used to give a rapid indication of the optimal combination of production factors within the herd.

This lack of application of the EVOP approach in dairy production could be due to 2 challenges. The first challenge, valid mostly in the past, was the absence of sufficient data collected during the production process. Nowadays, this is hardly an obstacle due to increasing amount of farmers investing in automatic milking systems (AMS), automatic estrus detections systems, and other technologies with automatic data recording. The second, so far unsolved challenge, is the lack of a flexible tool to dynamically estimate the effect of the intervention made to a dairy cattle production system.

The decision support tools currently used in dairy operations are based mainly on key figures, and in some cases on time series analyses, multifactorial analyses, and simulations, each with their own strengths. But when it comes to evaluating the effect of a given change in production method (e.g., feed supplement, grouping of cows, mastitis prevention) in a local situation, the existing systems lack the ability to control for potential confounders and may involve selection bias. In that respect, a potential EVOP tool should fill a gap in the existing systems rather than being an alternative to them.

An efficient tool to be used in EVOP experimental interventions should meet also other requirements. Because the EVOP concept is based on systematic experimentation within an ongoing production process, a tool used for estimating the effect of these systematic changes should provide results frequently (e.g., on daily basis), so that any negative changes to production would be noticed almost immediately and the experiment could be discontinued without major financial losses for a farmer. Moreover, to be used as farm decision support, a tool should not only provide estimates of the mean of the intervention effect but also quantify the uncertainty about the true value of the intervention (i.e., provide estimates regarding variance). In addition, a flexible tool should be able to use data collected from different sources (e.g., daily milk production from AMS, bulk tank, or test-day milkings).

A method based on a dynamic linear model (DLM) with Kalman filtering fulfills all requirements listed above. DLM have been widely applied in effect evaluation (West and Harrison, 1997). In dairy production, only 3 applications of DLM with Kalman filtering were described until 2009 (De Vries and Reneau, 2010). Dynamic linear model have been used in monitoring bulk tank SCC in milk (Thysen, 1993), in detecting estrus and diseases in dairy cattle (de Mol et al., 1999), and in monitoring daily milk production (Van Bebber et al., 1999). In recent years, DLM have been used to estimate the production potential of cows as a basis for optimal replacement policies (Nielsen et al., 2010), for prediction of dairy cow mastitis (Jensen et al., 2016), as well as to determine whether dairy cows with subclinical mammary infections recover after antibiotic treatment (Jørgensen et al., 2016). The model constructed by Van Bebber et al. (1999) was used to detect significant changes in the milk production of both individual cows and an entire herd, and could be used in exploiting changes occurring during normal (non-EVOP) production flow in the dairy herd. However, to our knowledge, DLM have not been used with the focus on estimating the effect of EVOP interventions in dairy herds.

A large amount of data on milk production is being accumulated in dairy herds. For example, over 1 million test-day records collected across herds were used for prediction of daily milk, fat, and protein production (Mayeres et al., 2004) or to identify sources of variation able to explain differences between herds in milk production (Caccamo et al., 2010). However, when constructing a decision support tool used for on-farm process optimization, farm-specific data should be used. This is particularly important, as pointed out by Toft and Jørgensen (2002), due to the fact that application of parameters that are common to all herds in a decision support system might lead to flawed results.

The objective of this study was to construct a tool able to estimate the effect of an intervention on milk yield using farm-specific production data collected during the ongoing production process. Furthermore, the aim of this study was to test the constructed tool on 
Table 1. Description of data set used to estimate milk yield parameters in herds 1 and 2

\begin{tabular}{|c|c|c|c|c|}
\hline Herd number & $\begin{array}{l}\text { Lactation } \\
\text { no. }\end{array}$ & $\begin{array}{c}\text { No. of } \\
\text { observed cows }\end{array}$ & $\begin{array}{c}\text { No. of } \\
\text { observed milkings }\end{array}$ & $\begin{array}{l}\text { Average milk } \\
\text { yield, } \mathrm{kg}\end{array}$ \\
\hline \multicolumn{5}{|c|}{ Observations used for model building } \\
\hline \multirow[t]{2}{*}{$1^{1}$} & 1 & 181 & 36,644 & 29.7 \\
\hline & $\geq 3$ & 122 & 29,879 & 39.7 \\
\hline \multirow[t]{2}{*}{$2^{2}$} & 1 & 155 & 1,442 & 29.2 \\
\hline & 2 & 93 & 918 & 35.7 \\
\hline \multirow[t]{3}{*}{$1^{1}$} & 1 & 84 & 3,297 & 30.8 \\
\hline & 2 & 79 & 3,693 & 37.1 \\
\hline & $\geq 3$ & 86 & 5,143 & 40.6 \\
\hline \multirow[t]{3}{*}{$2^{3}$} & 1 & 97 & 85 & \\
\hline & 2 & 65 & 85 & \\
\hline & $\geq 3$ & 72 & 85 & \\
\hline $2^{2}$ & $\overline{1}$ & 94 & 577 & 29.6 \\
\hline
\end{tabular}

${ }^{1}$ Data collected from automatic milking system.

${ }^{2}$ Data collected during the test days.

${ }^{3}$ Data collected from 85 bulk tank registrations.

different experimental designs (a treatment and control group design and a pretest/posttest design) as well as using different data sources (data from an AMS, bulk milk yield data, test-day milk data).

\section{MATERIALS AND METHODS}

\section{Data from the Herds}

To construct and test a tool able to estimate the effect of interventions on milk yield, data from 2 Danish commercial herds were collected. Data from each herd were divided into 2 sets (building and testing set). The data set used for testing included the time period in which the EVOP experiments were conducted.

Description of Herd 1. The herd, of approximately 240 Holstein cows, was housed in a loose housing system with slatted floor and cubicles with straw bedding. The lactating cows were divided in 2 equal-sized dynamic groups, each with access to 2 Lely AMS (Lely Agrartechnik GmbH, Waldstetten, Germany) in each group. During the experiment, average daily milking frequency was 3 and 3.2 per cow in the 2 groups. Concentrate, a mix of barley and soy, was provided according to stage of lactation and milk yield to the cows in the AMS. A partial mixed ration (PMR) consisting of $48 \%$ maize silage, $36 \%$ grass silage, $14 \%$ concentrate, $1 \%$ mineral mix, with a calculated net energy content of $6.56 \mathrm{MJ}$ per $\mathrm{kg}$ of $\mathrm{DM}$ and $15.6 \% \mathrm{CP}$ was fed ad libitum once a day at the feed bunk.

Herd 1-Historical Data Used for Modeling Milk Yield. Milk yield data in this herd was collected from the AMS between July 2013 and March 2015. The data set used in analyses consisted of 98,046 daily milk yield observations registered for 325 cows (Table 1).

Herd 1-EVOP Experiment Design. In this herd, the experiment was focusing on feeding. The EVOP experiment was designed to explore the possibility of reducing the amount of concentrate provided to the cows in the AMS and instead supply a similar amount of energy in the PMR provided to the cows at the feed bunk. From a herd management perspective, this would be economically sound because energy provided in the PMR is cheaper than energy provided as concentrate fed separately in the AMS. Therefore, the main goal was to see if we could avoid negative consequences in milk yield when changing energy amounts provided in the AMS and the PMR. The EVOP experiment (graphically illustrated in Figure 1) consisted of the following steps: on March 23, 0.85 $\mathrm{kg} /$ cow per day of soy-based concentrate was removed from the AMS and the energy concentration in the PMR was increased, so the total planned average energy intake in $\mathrm{MJ} / \mathrm{cow}$ per day remained constant. Subsequently, the herd was split in 2 groups (group 1 and group 2) based on AMS. In the treatment group (group 2), the energy provided to the cows in the AMS was sequentially reduced (April 21 and May 20) by $0.2 \mathrm{~kg}$ of barley and $0.2 \mathrm{~kg}$ of soybean meal. Group 1 served as a control group that was given the same PMR as group 2 and remained at the original level of concentrate of the AMS. Therefore, cows from group 2 would have to increase the intake of PMR to keep the same energy intake as group 1.

Herd 1-EVOP Experiment Justification. There are several reasons for providing a certain amount of 
Herd 1 - EVOP experiment

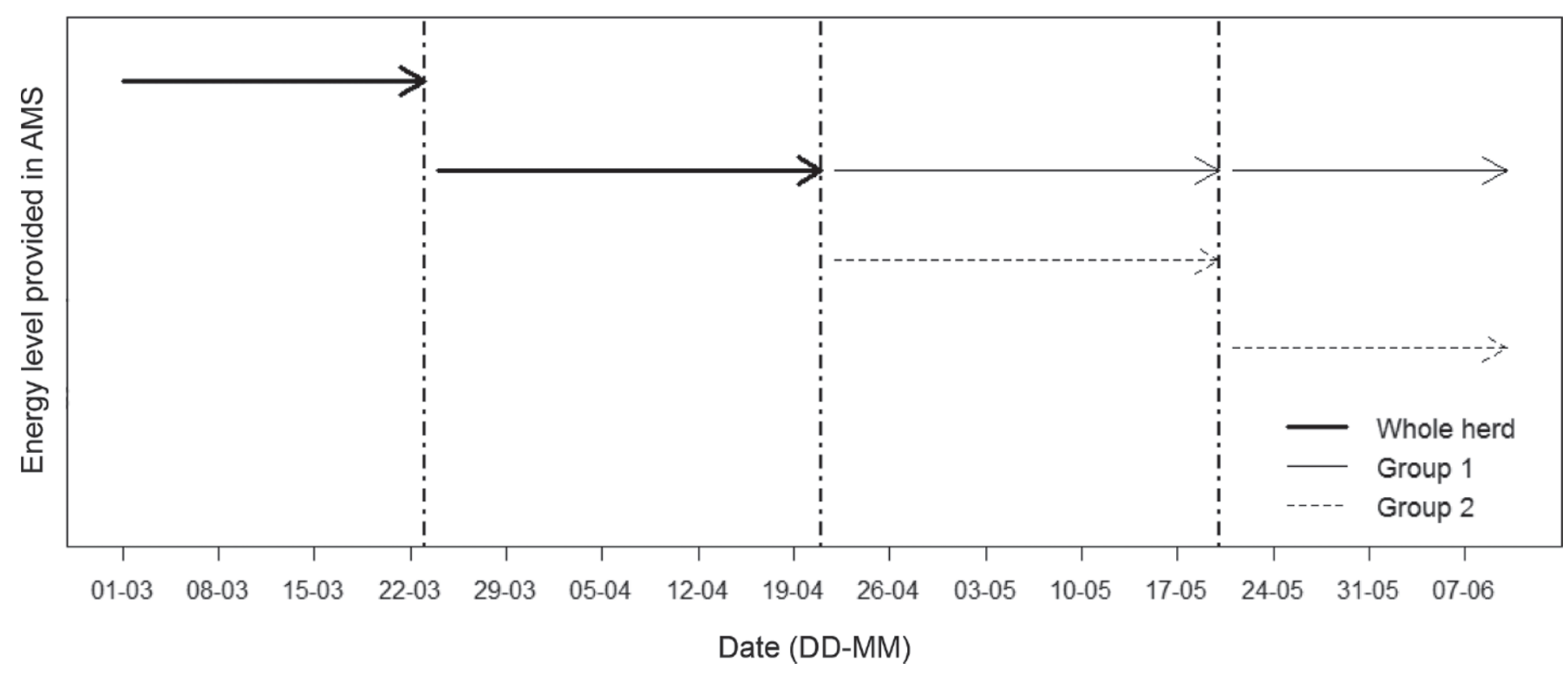

Figure 1. Schematic representation of an evolutionary operations (EVOP) experiment with treatment and control group design in herd 1. Vertical dashed-dotted lines mark the intervention dates. AMS = automatic milking system.

concentrate in AMS. As reviewed by Jacobs and Siegford (2012), one reason is to supplement an individual cow to support her stage of lactation, anticipated milk yield, or body condition. Another reason for concentrate supplementation is simply to attract the cows to an AMS (Halachmi et al., 2009). Because, as reported by previous studies, no differences were present in milk production between cows with the same total ration (TMR) but offered low $(3 \mathrm{~kg} / \mathrm{d})$ or high $(8 \mathrm{~kg} / \mathrm{d})$ amount of concentrate in the AMS (Bach et al., 2007), farm managers using higher amounts of concentrate provided in AMS can consider reducing this amount. However, due to farm differences (e.g., differences in feed ration characteristics), the question is how much to reduce and what will be the effect of concentrate reduction on milk production in a particular herd? To answer these questions, we have used the constructed DLM to explore the effect of reducing concentrate provided in the AMS in herd 1.

Description of Herd 2. The herd of approximately 245 Red Danish cows was housed in a loose housing system with slatted floor and cubicles with straw bedding, milking twice a day in a $2 \times 11$ head milking parlor. The lactating cows were housed in one group with access to a TMR (Table 2). Cows were fed ad libitum once a day at the feed bunk, which had space for only half of the cows at a time. The amount $(\mathrm{kg})$ of each feed item loaded into the mixer and the amount left over at the feed bunk were measured daily. The net energy content was estimated according to the NorFor
(Volden, 2011) based on feed analysis of roughage every second week and standard values for concentrates.

Herd 2-Historical Data Used for Modeling Milk Yield. Milk yield data (expressed as ECM) in this herd were collected between July 2013 and March 2015. The data set used in the analyses consisted of 3,689 test-day milk yield recordings of 286 cows collected approximately every 5 wk (Table 1 ). Raw milk yield data were corrected for fat and protein content according to the equation of Sjaunja et al. (1990):

$$
\operatorname{ECM}(\mathrm{kg})=\operatorname{Milk}(\mathrm{kg}) \times\left[\begin{array}{l}
(383 \times \text { fat } \%+242 \times \text { protein } \% \\
+783.2) / 3,140
\end{array}\right]
$$

where fat $\%$ and protein $\%$ are fat and protein percentage measured on the test day.

Herd 2-EVOP Experiment Design. The herd manager wanted to explore if the milk production could be increased by increasing the energy level provided to the cows in the TMR. This was of special concern to first lactation cows, where the higher energy concentration in the TMR should be able to reduce the feeding time for cows in second or higher lactations and thereby leave more room and time available at the feed bunk for cows in first lactation. The experiment (graphically illustrated on Figure 2) was planned to have a $5 \mathrm{MJ}$ increase in energy intake per cow per day every $4 \mathrm{wk}$. The first increase in TMR energy was on 
Table 2. Changes in composition and energy concentration (MJ per kg of DM) of TMR during evolutionary operation (EVOP) experiment in herd 2

\begin{tabular}{|c|c|c|c|c|}
\hline TMR property & $\begin{array}{l}\text { Before the first } \\
\text { intervention }\end{array}$ & $\begin{array}{l}\text { First intervention } \\
\text { (Mar. 10, 2015) }\end{array}$ & $\begin{array}{l}\text { Second intervention } \\
\quad(\text { Apr. 9, 2015) }\end{array}$ & $\begin{array}{l}\text { Third intervention } \\
\text { (May 12, 2015) }\end{array}$ \\
\hline \multicolumn{5}{|l|}{ Composition of TMR, \% of DM } \\
\hline Soybean meal & 13 & 14 & 15 & 15 \\
\hline Beet pellets & 0 & 0 & 0 & 5 \\
\hline Fat & 0 & 0 & 0 & 1 \\
\hline Straw & 1 & 0 & 0 & 0 \\
\hline Mineral & 1 & 1 & 1 & 1 \\
\hline Net energy content, MJ per $\mathrm{kg}$ of DM & 6.56 & 6.65 & 6.72 & 6.75 \\
\hline
\end{tabular}

March 10, 2015, the second was on April 9, 2015, and the final, third increase was on May 12, 2015. Composition and energy concentration (MJ per $\mathrm{kg}$ of DM) of TMR before the first intervention as well as for all 3 interventions is presented in Table 2. The experimental design can be considered a before-after (pretest/posttest) design without a control group. Unfortunately, the achieved increases in energy concentration in the TMR did not support the planned increase in herd feed intake so the actual increase in energy intake was only 2 and 3 $\mathrm{MJ} /$ cow per $\mathrm{d}$ in the first 2 interventions, respectively. At the third intervention, the increase in actual energy intake was $6 \mathrm{MJ} /$ cow per d.

Herd 2-EVOP Experiment Justification. Chewing time (sum of eating and rumination time) is highly negatively correlated with energy concentra- tion of the feeding ratio (Volden, 2011). Therefore, one might suspect that increasing energy concentration in a TMR would be able to reduce time spent at the feed bunk by multiparous cows and provide more space and time for primiparous cows. Thus, an increase in energy concentration in a TMR can potentially lead to increased milk production for primiparous cows as well as for the whole herd. To evaluate this theory, we have conducted and analyzed the feeding experiment in the specific environmental conditions of herd 2 .

Data Used for Testing. The tool was tested on data collected from herd 1 and herd 2 (Table 1) during EVOP experimental interventions.

For herd 1, from 1 to 4 daily milkings per cow registered in the AMS were aggregated into 24-h milk production. The milk record from the first milking after

\section{Herd 2 - EVOP experiment}

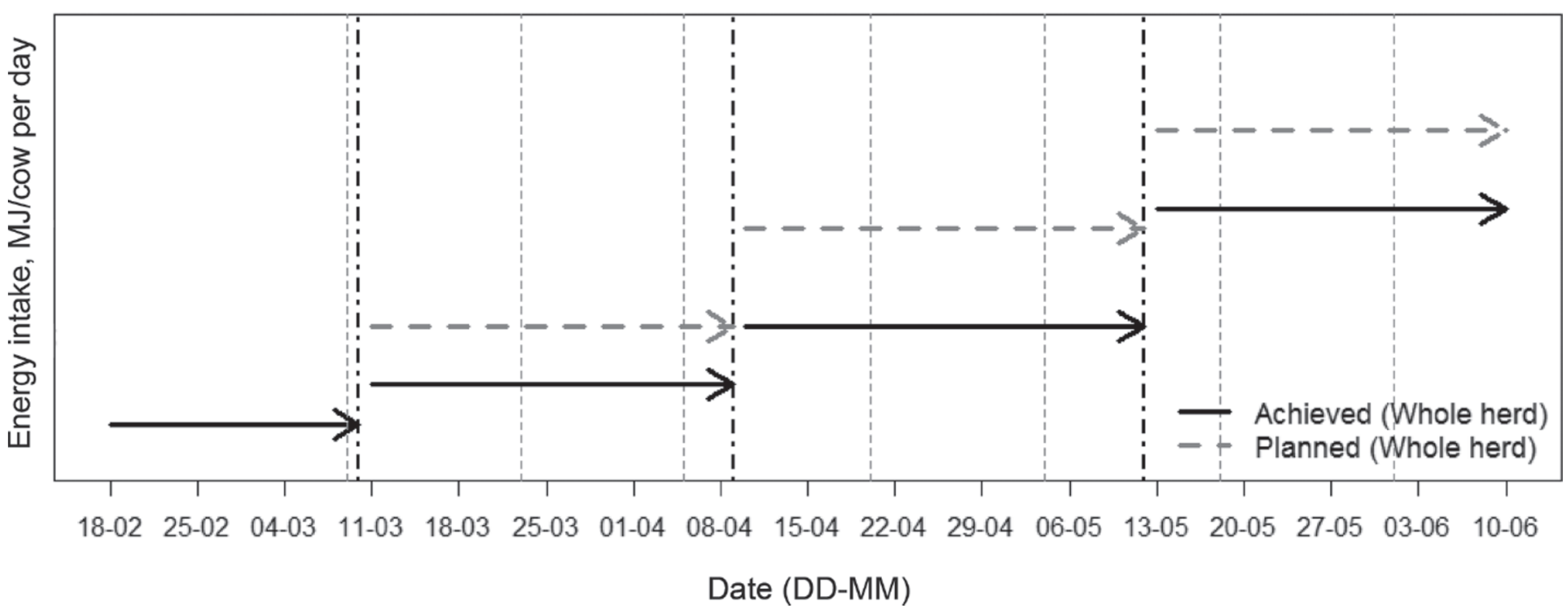

Figure 2. Schematic representation of an evolutionary operations (EVOP) experiment with pretest/posttest design in herd 2. Vertical dashed-dotted lines mark the intervention dates. Vertical dashed lines mark test-day recordings. 
midnight was split on the two 24 -h periods relative to the time from milking to midnight. Altogether, 12,133 observations of individual cows' milk production during $24 \mathrm{~h}$ were obtained.

In herd 2, the 1,471 individual observation of milk yield collected during the test-day recordings on approximately every second week were supplemented with 85 observations of herd bulk tank milk, corrected for discarded milk.

\section{Modeling Milk Yield}

To construct a model able to estimate the effect of interventions on milk yield, historical knowledge on milk yield achieved in the herds was used. To gain knowledge on milk production from herd 1 and herd 2, the historical data were used (Table 1). The milk yield $\left(Y_{i j d}\right)$, expressed in kilograms of raw milk for herd 1 and kilograms of ECM for herd 2 of a cow $i$ in a particular day $d$ of lactation $j$, was modeled at the herd and cow level using 4 parameters so that

$$
Y_{i j d}=\mu_{j d}+A_{i j}+X_{i j d}+v_{i j d}
$$

where $\mu_{j d}$ was the average herd milk yield on lactation day $d$ for cows in lactation $j, A_{i j}$ was the production potential of cow $i$ in lactation $j$, with $A_{i j} \sim N\left(0, \sigma_{A}^{2}\right)$, where $\sigma_{A}$ is the variance in the production potential of a cow. The variable $X_{i j d} \sim N\left(0, \sigma_{X}^{2}\right)$, where $\sigma_{X}$ was a variance in the local production effect, represented a local production effect on milk yield as a result of temporary environmental effects and was modeled as an autoregressive process of order 1 with mean 0 and autocorrelation $\rho$; that is,

$$
X_{i j d}=\rho X_{i j, d-1}+\varepsilon_{i j d},
$$

in which $\varepsilon_{i j d} \sim N\left[0,\left(1-\rho^{2}\right) \sigma_{X}^{2}\right]$. Finally, the model was supplemented by a measurement error $v_{i j d}$. It was assumed that $v_{i j d} \sim N\left(0, \sigma_{v}^{2}\right)$, where $\sigma_{v}$ was a variance in observational error.

In this study, 3 possible lactation curves (for lactation 1,2 , and $\geq 3$ ) were considered. The herd milk yield was modeled using an approach based on 2 linear functions with 2 parameters each, as described by Bennedsgaard et al. (2003). The reason to select this approach for modeling milk yield is its direct applicability to a dynamic linear model. Moreover, the application of the tool requires that the lactation curve parameters should be estimated in every new herd. This has an effect on the trade-off between complexity and robustness and was in favor of the latter. Therefore, a well-established lactation curve model with fixed peak and few parameters was chosen. The first linear function described the milk yield during the first $60 \mathrm{~d}$ after calving (where $\phi_{2, j}$ is a slope of lactation function during the first 60 $\mathrm{d}$ and $\phi_{1, j}$ is milk yield $60 \mathrm{~d}$ after calving). The second function described the remaining milk yield (where $\phi_{3, j}$ is a slope of lactation function after the first $60 \mathrm{~d}$ and $\phi_{1, j}$ is milk yield $60 \mathrm{~d}$ after calving). Thus, we have

$$
\mu_{j d}=\left\{\begin{array}{l}
\phi_{1, j}-(60-d) \phi_{2, j}, d \leq 60 \\
\phi_{1, j}-(d-60) \phi_{3, j}, d>60
\end{array} .\right.
$$

For 3 lactation curves, we will have a total of 9 lactation curve parameters. Values estimated from the model are summarized in Table 3 (herd 1) and Table 4 (herd 2); moreover, a graphical representation of the lactation curves is presented in Figure 3. The obtained parameters were used for specifying variance components as well as setting the initial distribution of the parameter vector in a multivariate dynamic linear model.

Table 3. Milk yield parameters estimated for herd $1^{1}$

\begin{tabular}{lllll}
\hline Parameter & Symbol $^{2}$ & Lactation 1 & Lactation 2 & Lactation $\geq 3$ \\
\hline Milk yield 60 d after calving, $\mathrm{kg}$ & $\phi_{1, l}$ & $35.21(0.36)$ & $45.55(0.50)$ & $47.80(0.61)$ \\
Slope over the first 60 DIM, $\mathrm{kg}$ & $\phi_{2, l}$ & $29.61 \times 10^{-2}(0.01)$ & $31.61 \times 10^{-2}(0.01)$ & $33.30 \times 10^{-2}(0.01)$ \\
Slope after 60 DIM, kg & $\phi_{3, l}$ & $-4.83 \times 10^{-2}(0.002)$ & $-8.92 \times 10^{-2}(0.002)$ & $-9.78 \times 10^{-2}(0.002)$ \\
Variance in the production potential of a cow & $\sigma_{A_{l}}^{2}$ & 14.19 & 15.29 & 36.10 \\
Variance in a local production effect & $\sigma_{X_{l}}^{2}$ & 17.63 & 4.21 & 60.37 \\
Observational error & $\sigma_{v_{l}}^{2}$ & 3.95 & 0.98 & 5.61 \\
Auto-correlation of local production effect & $\rho_{l}$ & 0.97 & 0.98 \\
\hline
\end{tabular}

${ }^{1} \mathrm{SD}$ in parentheses.

${ }^{2} l$ in the subscript refers to lactation number. 
Table 4. Milk yield parameters estimated for herd $2^{1}$

\begin{tabular}{lllll}
\hline Parameter & Symbol $^{2}$ & Lactation 1 & Lactation 2 & Lactation $\geq 3$ \\
\hline Milk yield $60 \mathrm{~d}$ after calving, $\mathrm{kg}$ & $\phi_{1, l}$ & $29.27(0.75)$ & $39.25(1.16)$ & $40.01(0.98)$ \\
Slope over the first $60 \mathrm{DIM}, \mathrm{kg}$ & $\phi_{2, l}$ & $8.64 \times 10^{-2}(0.02)$ & $6.43 \times 10^{-2}(0.03)$ & $6.37 \times 10^{-2}(0.02)$ \\
Slope after 60 DIM, ${ }^{2} \mathrm{~kg}$ & $\phi_{3, l}$ & $-3.47 \times 10^{-2}(0.005)$ & $-8.13 \times 10^{-2}(0.007)$ & $-8.93 \times 10^{-2}(0.006)$ \\
Variance in the production potential of a cow & $\sigma_{A_{l}}^{2}$ & 2.92 & 16.88 & 13.87 \\
Variance in a local production effect & $\sigma_{X_{l}}^{2}$ & 116.75 & $1.37 \times 10^{-5}$ & 87.99 \\
Observational error & $\sigma_{v_{l}}^{2}$ & 2.82 & 0.99 & 3.19 \\
Auto-correlation of local production effect & $\rho_{l}$ & 0.99 & 0.99 \\
\hline
\end{tabular}

${ }^{1} \mathrm{SD}$ in parentheses.

${ }^{2} l$ in the subscript refers to lactation number.

\section{Multivariate Dynamic Linear Model}

Model Structure. A multivariate DLM was constructed to describe milk yield using historical data. A DLM consists of an observation equation (Equation [5]) and a system equation (Equation [6]) as described by West and Harrison (1997):

$$
\begin{gathered}
\mathbf{Y}_{t}=\mathbf{F}_{t}^{\prime} \boldsymbol{\theta}_{t}+\mathbf{v}_{t}, \mathbf{v}_{t} \sim N\left(\underline{\mathbf{0}}, \mathbf{I} \sigma_{v}^{2}\right), \\
\boldsymbol{\theta}_{t}=\mathbf{G}_{t} \boldsymbol{\theta}_{t-1}+\mathbf{w}_{t}, \mathbf{w}_{t} \sim N\left(\underline{\mathbf{0}}, \mathbf{W}_{t}\right),
\end{gathered}
$$

where $\mathbf{Y}_{t}$ was an observation vector, $\boldsymbol{\theta}_{t}$ was a vector of parameters at time $t, \mathbf{F}_{t}$ was a matrix of coefficients (the design matrix), $\mathbf{v}_{t}$ was a random observation error, $\underline{\mathbf{0}}$ was a vector of zeros, $\mathbf{I}$ was the identity matrix, $\mathbf{G}_{t}$ was a system matrix, and $\mathbf{W}_{t}$ was a variance-covariance matrix.

The observation equation (Equation [5]) linked observations to the parameters. The observation vector $\mathbf{Y}_{t}=\left(y_{1 t}, \ldots, y_{N t}\right)^{\prime}$ consisted of observed milk yields (either raw milk yield for herd 1 or ECM for herd 2) of all $N$ cows that have been milked at day $t$. Dry cows and cows of which the milk has been discarded, for instance because of medical treatment, are left out of the observation vector.

The observations are modeled by a latent parameter vector $\boldsymbol{\theta}_{t}$, which was split into 3 subvectors, $\phi_{t}, \boldsymbol{\psi}_{t}$, and $\boldsymbol{\lambda}_{t}$ so that $\boldsymbol{\theta}_{t}=\left(\phi_{t}, \boldsymbol{\psi}_{t}, \boldsymbol{\lambda}_{t}\right)^{\prime}$. The first subvector, $\boldsymbol{\phi}_{t}=$
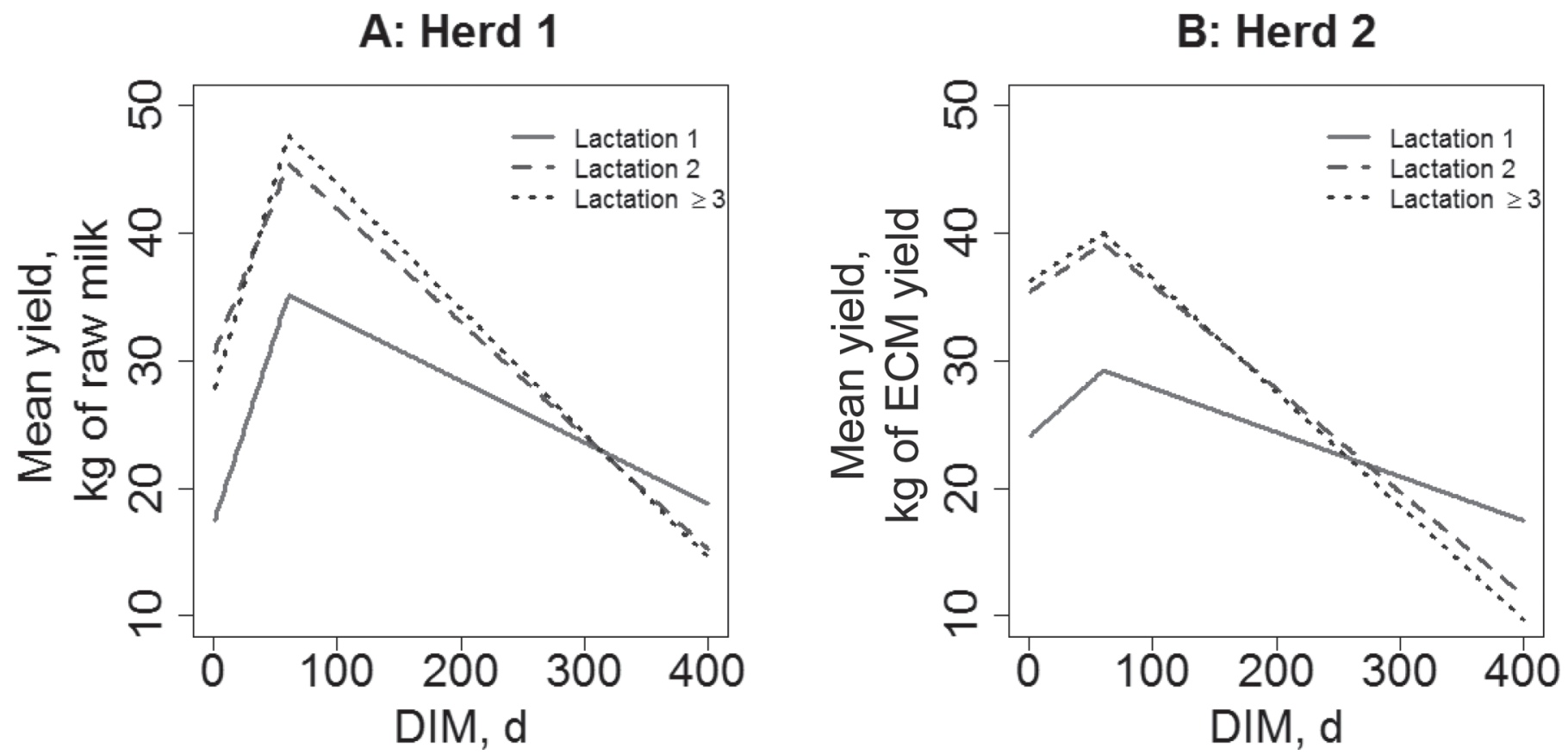

Figure 3. Lactation curves (daily milk yield as a function of DIM) for parities 1,2 , and $\geq 3$ estimated based on available data for (A) herd 1 and (B) herd 2. 
$\left(\phi_{11 t}, \ldots, \phi_{33 t}\right)^{\prime}$, contained the 9 parameters describing the shape of the 3 lactation curves at time $t$. It corresponds to the herd level of the milk yield model. The second subvector contained the parameters describing the individual cows in the herd (with 2 parameters per cow) and has the form $\boldsymbol{\psi}_{t}=\left(A_{1, j_{1}, t}, \ldots, A_{N, j_{N}, t}, X_{1, j_{1}, t}, \ldots, X_{N, j_{N}, t}\right)^{\prime}$. The third subvector, $\boldsymbol{\lambda}_{t}$, described the effect of intervention on day $t$ : $\boldsymbol{\lambda}_{t}=\left(\boldsymbol{\lambda}_{1 t}, \boldsymbol{\lambda}_{2 t}, \boldsymbol{\lambda}_{3 t}\right)^{\prime}$. In this case, 3 interventions were considered.

Using the information from parameter vector $\boldsymbol{\theta}_{t}$, milk yield of any given cow from a herd during lactation can be identified. For example, by selecting from vector $\boldsymbol{\theta}_{t}$ parameters corresponding to a given cow and inserting them into the Equation [2] and Equation [4], we can obtain the following milk yield plots (Figure 4). Separate lines were plotted for herd milk yield and milk yield together with information on cow effect, environment effect, measurement error, and intervention effect.

The role of the design matrix $\mathbf{F}_{t}$ was to indicate which parameters from the vector $\boldsymbol{\theta}_{t}$ were observed. The design matrix can be decomposed so that
$\mathbf{F}_{t}^{\prime}=\left(\mathbf{F}_{t}^{\phi}, \mathbf{F}_{t}^{\psi}, \mathbf{F}_{t}^{\mathbf{\lambda}}\right)$. The dimensions of the design matrix were changing depending on the herd size as well as number of observations taken during $1 \mathrm{~d}$. The number of cows observed during $1 \mathrm{~d}$ determined the number of rows in $\mathbf{F}_{t}{ }^{\prime}$, whereas number of cows in the herd determined the number of columns in $\mathbf{F}_{t}^{\psi}$. Through the design matrix, the model can handle cows in different stages of lactation. To illustrate how the design matrix is built, let us consider modeling a herd with only 5 cows (cows have following numbers in the herd: 1, 2, 3, $5,6)$, which at the time $t$ are in lactation $1, \geq 3,2,2,1$ and DIM 31, 71, 90, 235, 1, respectively. Moreover, at time $t$ only the first 3 cows (with number $1,2,3$ ) participated in an experiment. For that example, we would obtain the following design matrices:

$$
\mathbf{F}_{t}^{\phi}=\left(\begin{array}{ccccccccc}
1 & -31 & 0 & 0 & 0 & 0 & 0 & 0 & 0 \\
0 & 0 & 0 & 0 & 0 & 0 & 1 & 0 & -11 \\
0 & 0 & 0 & 1 & 0 & -30 & 0 & 0 & 0 \\
0 & 0 & 0 & 1 & 0 & -175 & 0 & 0 & 0 \\
1 & 0 & -1 & 0 & 0 & 0 & 0 & 0 & 0
\end{array}\right),
$$
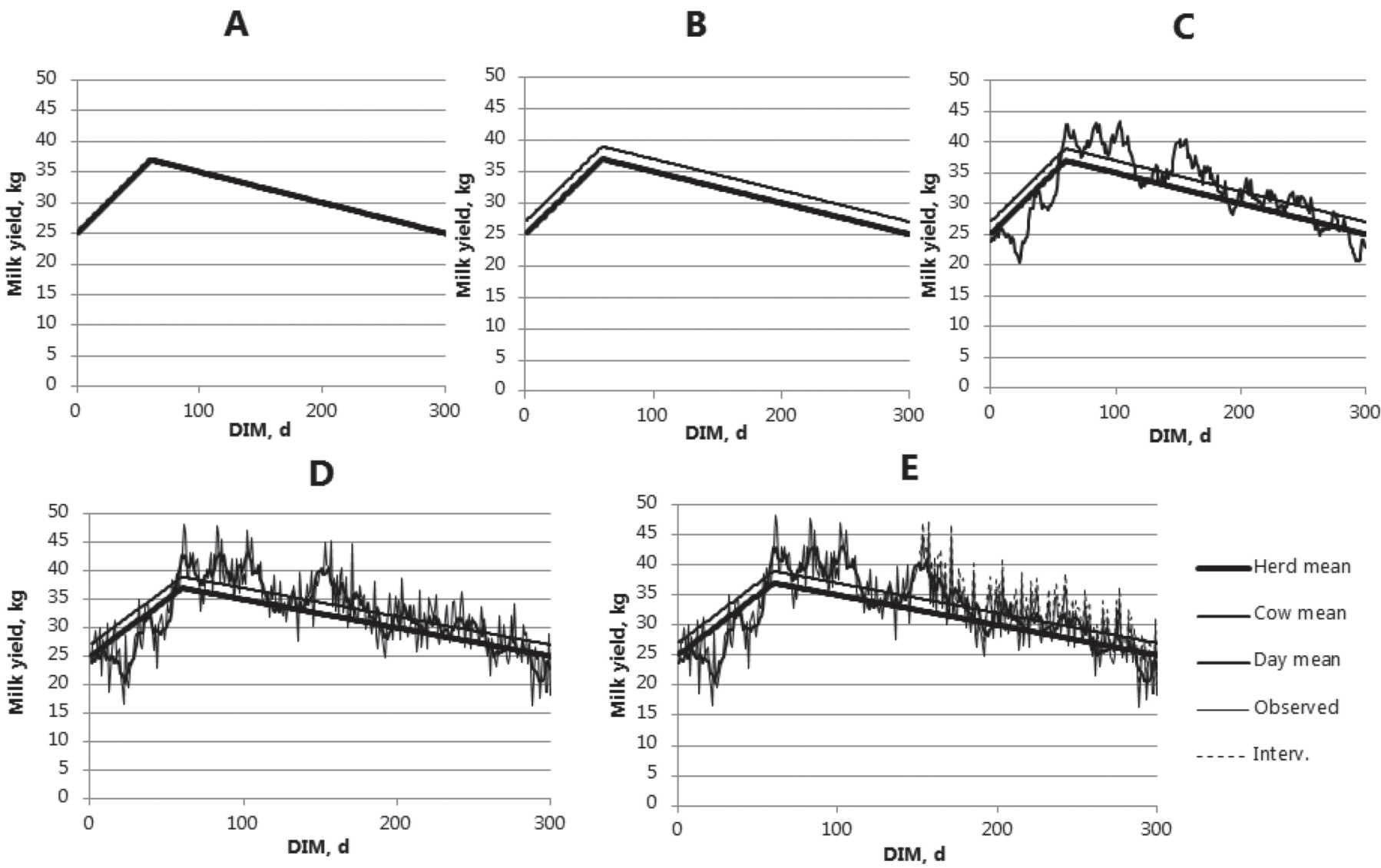

Figure 4. Lactation curve of an example cow for which milk yield was plotted using information on (A) herd milk yield; (B) herd milk yield and cow effect; (C) herd milk yield, cow effect, and environmental effect; (D) herd milk yield, cow effect, environmental effect, and measurement error; and (E) herd milk yield, cow effect, environmental effect, measurement error, and intervention (Interv.) parameter. 


$$
\begin{aligned}
& \mathbf{F}_{t}^{\psi}=\left(\begin{array}{cccccccccc}
1 & 0 & 0 & 0 & 0 & 1 & 0 & 0 & 0 & 0 \\
0 & 1 & 0 & 0 & 0 & 0 & 1 & 0 & 0 & 0 \\
0 & 0 & 1 & 0 & 0 & 0 & 0 & 1 & 0 & 0 \\
0 & 0 & 0 & 1 & 0 & 0 & 0 & 0 & 1 & 0 \\
0 & 0 & 0 & 0 & 1 & 0 & 0 & 0 & 0 & 1
\end{array}\right), \text { and } \\
& \mathbf{F}_{t}^{\lambda}=\left(\begin{array}{ccc}
1 & 0 & 0 \\
1 & 0 & 0 \\
1 & 0 & 0 \\
0 & 0 & 0 \\
0 & 0 & 0
\end{array}\right)
\end{aligned}
$$

The matrix $\mathbf{F}_{t}^{\boldsymbol{\lambda}}$ of the presented example consists of 3 columns. Each column is intended for a separate intervention parameter; therefore, in this version of the model, 3 consecutive interventions could be evaluated. In the example above (Equation [9]), only the first intervention took place.

The system equation expresses how the parameter values may change over time. The system matrix can be decomposed as a block-diagonal matrix of the following form:

$$
\mathbf{G}_{t}=\left(\begin{array}{ccc}
\mathbf{I} & \mathbf{0} & \mathbf{0} \\
\mathbf{0} & \mathbf{G}_{t}^{\psi} & \mathbf{0} \\
\mathbf{0} & \mathbf{0} & \mathbf{I}
\end{array}\right)
$$

where I represents identity matrices of appropriate dimensions, $\mathbf{0}$ represents matrixes only consisting of zeros, and $\mathbf{G}_{t}^{\psi}$ is a submatrix describing the evolution of a cow-specific parameter in $\boldsymbol{\psi}_{t}$. Similarly, the error term $\mathbf{w}_{t}$ is split into 3 subvectors so that $\mathbf{w}_{t}=\left(\mathbf{0}, \mathbf{w}_{t}^{\boldsymbol{\psi}}, \mathbf{0}\right)^{\prime}$. Thus, Equation [6] can be written as 3 separate matrix equations:

$$
\begin{gathered}
\phi_{\boldsymbol{t}}=\phi_{t-1} \\
\psi_{t}=\mathbf{G}_{t}^{\psi} \psi_{t-1}+\boldsymbol{w}_{t}^{\psi}, \mathbf{w}_{t}^{\psi} \sim N\left(\underline{\mathbf{0}}, \mathbf{W}_{t}^{\psi}\right) \\
\boldsymbol{\lambda}_{t}=\boldsymbol{\lambda}_{t-1} .
\end{gathered}
$$

The dimensions of $\mathbf{G}_{t}$ and $\mathbf{w}_{t}$ depend on the number of parameters from vector $\boldsymbol{\theta}_{t}$ and therefore will be changing for different herds.

The DLM can handle situations where a cow is replaced. In the example used for illustrating how to construct the design matrix we had cow 6 which just started the first lactation. Let us assume that this cow replaced a cow with number 4 in the herd, which was culled from $t-1$ to $t$. In this case, the parameter subvectors $\psi_{t-1}$ and $\psi_{t}$ become

$$
\boldsymbol{\psi}_{t-1}=\left(\begin{array}{l}
A_{1,1, t-1} \\
A_{2,3, t-1} \\
A_{3,2, t-1} \\
A_{4,2, t-1} \\
A_{5,2, t-1} \\
X_{1,1, t-1} \\
X_{2,3, t-1} \\
X_{3,2, t-1} \\
X_{4,2, t-1} \\
X_{5,2, t-1}
\end{array}\right),
$$

with constant production potential of a $\operatorname{cow}\left(A_{i j t}=A_{i j, t-1}\right)$ and local environmental potential $\left(X_{i j t}=\rho X_{i j, t-1}+\varepsilon_{i j t}\right)$. The system submatrix converting $\psi_{t-1}$ to $\psi_{t}$ is

$$
\mathbf{G}_{t}^{\psi}=\left(\begin{array}{cccccccccc}
1 & 0 & 0 & 0 & 0 & 0 & 0 & 0 & 0 & 0 \\
0 & 1 & 0 & 0 & 0 & 0 & 0 & 0 & 0 & 0 \\
0 & 0 & 1 & 0 & 0 & 0 & 0 & 0 & 0 & 0 \\
0 & 0 & 0 & 0 & 1 & 0 & 0 & 0 & 0 & 0 \\
0 & 0 & 0 & 0 & 0 & 0 & 0 & 0 & 0 & 0 \\
0 & 0 & 0 & 0 & 0 & \rho & 0 & 0 & 0 & 0 \\
0 & 0 & 0 & 0 & 0 & 0 & \rho & 0 & 0 & 0 \\
0 & 0 & 0 & 0 & 0 & 0 & 0 & \rho & 0 & 0 \\
0 & 0 & 0 & 0 & 0 & 0 & 0 & 0 & 0 & \rho \\
0 & 0 & 0 & 0 & 0 & 0 & 0 & 0 & 0 & 0
\end{array}\right) .
$$


The culling of cow 4 is handled by a column of zeros at the positions of cow 4's parameters in vector $\boldsymbol{\theta}_{t}$. The insertion of cow number 6 is handled by a row of zeros at its position in the updated parameter vector, $\boldsymbol{\theta}_{t}$. Thus, the expected value of cow number 6 is 0 and independent of the previous parameter vector that did not contain it.

The variance-covariance matrix $\mathbf{W}_{t}$ is also a blockdiagonal of the form

$$
\mathbf{W}_{t}=\left(\begin{array}{ccc}
\mathbf{0} & \mathbf{0} & \mathbf{0} \\
\mathbf{0} & \mathbf{W}_{t}^{\psi} & \mathbf{0} \\
\mathbf{0} & \mathbf{0} & \mathbf{0}
\end{array}\right)
$$

where $\mathbf{0}$ represents matrixes only consisting of zeros and $\mathbf{W}_{t}^{\psi}$ is a diagonal matrix of the form

$$
\mathbf{W}_{t}^{\psi}=\left(\begin{array}{cccccccccc}
0 & 0 & 0 & 0 & 0 & 0 & 0 & 0 & 0 & 0 \\
0 & 0 & 0 & 0 & 0 & 0 & 0 & 0 & 0 & 0 \\
0 & 0 & 0 & 0 & 0 & 0 & 0 & 0 & 0 & 0 \\
0 & 0 & 0 & 0 & 0 & 0 & 0 & 0 & 0 & 0 \\
0 & 0 & 0 & 0 & \sigma_{A}^{2} & 0 & 0 & 0 & 0 & 0 \\
0 & 0 & 0 & 0 & 0 & \sigma_{\varepsilon}^{2} & 0 & 0 & 0 & 0 \\
0 & 0 & 0 & 0 & 0 & 0 & \sigma_{\varepsilon}^{2} & 0 & 0 & 0 \\
0 & 0 & 0 & 0 & 0 & 0 & 0 & \sigma_{\varepsilon}^{2} & 0 & 0 \\
0 & 0 & 0 & 0 & 0 & 0 & 0 & 0 & \sigma_{\varepsilon}^{2} & 0 \\
0 & 0 & 0 & 0 & 0 & 0 & 0 & 0 & 0 & \sigma_{X}^{2}
\end{array}\right),[18]
$$

in which $\sigma_{\varepsilon}^{2}=\left(1-\rho^{2}\right) \sigma_{X}^{2}, \sigma_{A}^{2}$ is variance in animal effect, and $\sigma_{X}^{2}$ is variance in temporary environmental effect. We have assumed that cows are unrelated (cows properties are assumed to be mutually independent within herd). Moreover, the variance component for a new cow (with no previous observations) is different from cases where former values $A_{i, j, t-1}$ and $X_{i, j, t-1}$ exist.

The flexibility of the tool was demonstrated by using different production data in evaluating the effect of intervention on milk yield. In herd 1, milk yield was modeled using data from the AMS, whereas in herd 2 it was a combination of production data collected during test days and data from the bulk tank collected every second day.

Each day, when milk yield observations were recorded, the DLM model was applied and the filtered values for the $\boldsymbol{\theta}_{t}$ vector (describing the shape of the lactation curve) were obtained. In this study we were interested to see how the intervention parameters $\boldsymbol{\lambda}_{t}$ from vector $\boldsymbol{\theta}_{t}$ can be estimated over time. The estimated value of the intervention parameters together with confidence intervals ( $\pm \mathrm{SD}$ and $\pm 2 \mathrm{SD}$ ) were plotted and analyzed for both experiments (Figure 5 and Figure 7).

Model Initialization. To initialize the DLM, the values for observational error $\left(\sigma_{v}^{2}\right)$, evolution error $\left(\sigma_{X}^{2}\right)$, and autocorrelation $(\rho)$ as well as initial distribution of vector of parameters $\boldsymbol{\theta}_{\mathbf{0}} \sim N\left(\mathbf{m}_{\mathbf{0}}, \mathbf{C}_{\mathbf{0}}\right)$ were obtained from herd data. All necessary parameters were obtained separately for each herd and lactation from the milk yield model (illustrated by Equation [1]) and are summarized in Tables 3 and 4 . The initial vector of parameters $\mathbf{m}_{\mathbf{0}}=\left[\phi_{1,1}, \phi_{2,1}, \phi_{3,1}, \phi_{1,2}, \phi_{2,2}, \phi_{3,2}, \phi_{1,3}, \phi_{2,3}, \phi_{3,3}, 0,0,0\right]^{\prime}$ consisted of mean values of herd effects in all 3 lactations for the first 9 parameters and zero for the parameter representing intervention effect. For the initial variance-covariance matrix $\left(\mathbf{C}_{0}\right)$, the following structure was assumed:

$$
\mathbf{C}_{0}=\left(\begin{array}{cccc}
\mathbf{C}^{\phi 1} & \mathbf{0} & \mathbf{0} & \mathbf{0} \\
\mathbf{0} & \mathbf{C}^{\phi 2} & \mathbf{0} & \mathbf{0} \\
\mathbf{0} & \mathbf{0} & \mathbf{C}^{\phi 3} & \mathbf{0} \\
\mathbf{0} & \mathbf{0} & \mathbf{0} & \mathbf{C}^{\lambda}
\end{array}\right)
$$

where $\mathbf{0}$ represents matrices only consisting of zeros; $\mathbf{C}^{\phi 1}, \mathbf{C}^{\phi 2}$, and $\mathbf{C}^{\phi 3}$ represent initial variance-covariance matrices for herd parameters in lactation 1,2 , and $\geq 3$, respectively. The matrix $\mathbf{C}^{\lambda}$ is a $3 \times 3$ diagonal with initial variance for intervention parameters. The initial variance for intervention effect was set to be 9 in both herds and for all interventions; therefore, the diagonal of $\mathbf{C}^{\lambda}$ is filled with 9 .

Parameters describing the permanent production potential of cow and a temporary production effect on milk yield were assumed to be drawn from normal distributions with variances $\sigma_{A}^{2}$ and $\sigma_{X}^{2}$, respectively, and did not require initialization because the values are automatically learned from data.

Running the Model with Data from the Bulk Tank. In herd 2, observations from test-day milking were supplemented with bulk milk data. If, in a particular day, milk from the bulk tank was observed, $\mathbf{Y}_{t}$ was no longer a vector, but a scalar, so that Equation [5] had the following form:

$$
\mathbf{Y}_{t}=\underline{\mathbf{1}} \boldsymbol{F}_{t}^{\prime} \boldsymbol{\theta}_{t}+\underline{\mathbf{1}} v_{t}, \underline{\mathbf{1}} v_{t} \sim N\left(0, \underline{\mathbf{1}} \sigma_{v}^{2}{\underline{\mathbf{1}^{\prime}}}^{\prime}\right)
$$


where 1 was a vector of ones. If detailed milk yield observations were available (data from individual milk yield), the DLM was applied as usual (Equation [5]).

Kalman Filter. The Kalman filter, described by West and Harrison (1997), was used for updating the distribution of the parameter vector $\boldsymbol{\theta}_{t}$ defined in the DLM. Based on all information available at time $t-1$ (milk yield, lactation number, and lactation stage of particular cow), the Kalman filter provided the prior distribution for $\boldsymbol{\theta}_{t}$, one-step forecast distribution for an observation vector $\mathbf{Y}_{t}$, and (after observation of $\mathbf{Y}_{t}$ ) the posterior distribution for $\boldsymbol{\theta}_{t}$. For a detailed description of the recursive algorithm, references to Kristensen et al. (2012) and Stygar and Kristensen (2016) are made.

\section{Data Analyses}

Data were plotted and analyzed in the $\mathrm{R}$ statistical software (R Core Team, 2014). The nlme package (Pinheiro et al., 2014) was used for modeling milk yield based on historical data. The model assessing the intervention effect on milk production in an EVOP setup was build using basic $\mathrm{R}$ functions.

\section{RESULTS AND DISCUSSION}

\section{EVOP in Herd 1}

Values of intervention parameter (solid line) together with confidence intervals $( \pm$ SD dotted line and \pm 2 SD dashed line) for herd 1 were presented on Figure 5. The results showed that, already $6 \mathrm{~d}$ after removing concentrate from the AMS and increasing energy concentration in the PMR, the lower confidence interval $(-2$ SD) for the first intervention parameter was above 0 (Figure 5A). Therefore, it was concluded that the first intervention resulted in a $0.8-\mathrm{kg}(\mathrm{SD} 0.16 \mathrm{~kg}$ ) increase in milk production. A further decrease in the amount of concentrate provided in AMS was explored. For the second and third intervention, herd 1 was divided into a control (group 1) and a treatment group (group 2). The consecutive reduction of concentrate in the AMS for group 2 resulted in the statistically significant increases in milk production after 23 and $9 \mathrm{~d}$ from the intervention dates, respectively (Figures $5 \mathrm{~B}$ and $5 \mathrm{C}$ ). The overall value for the intervention parameter after all 3 experiments was at the level of $2.9 \mathrm{~kg}(\mathrm{SD}=0.25$ $\mathrm{kg}$ ) of milk yield.
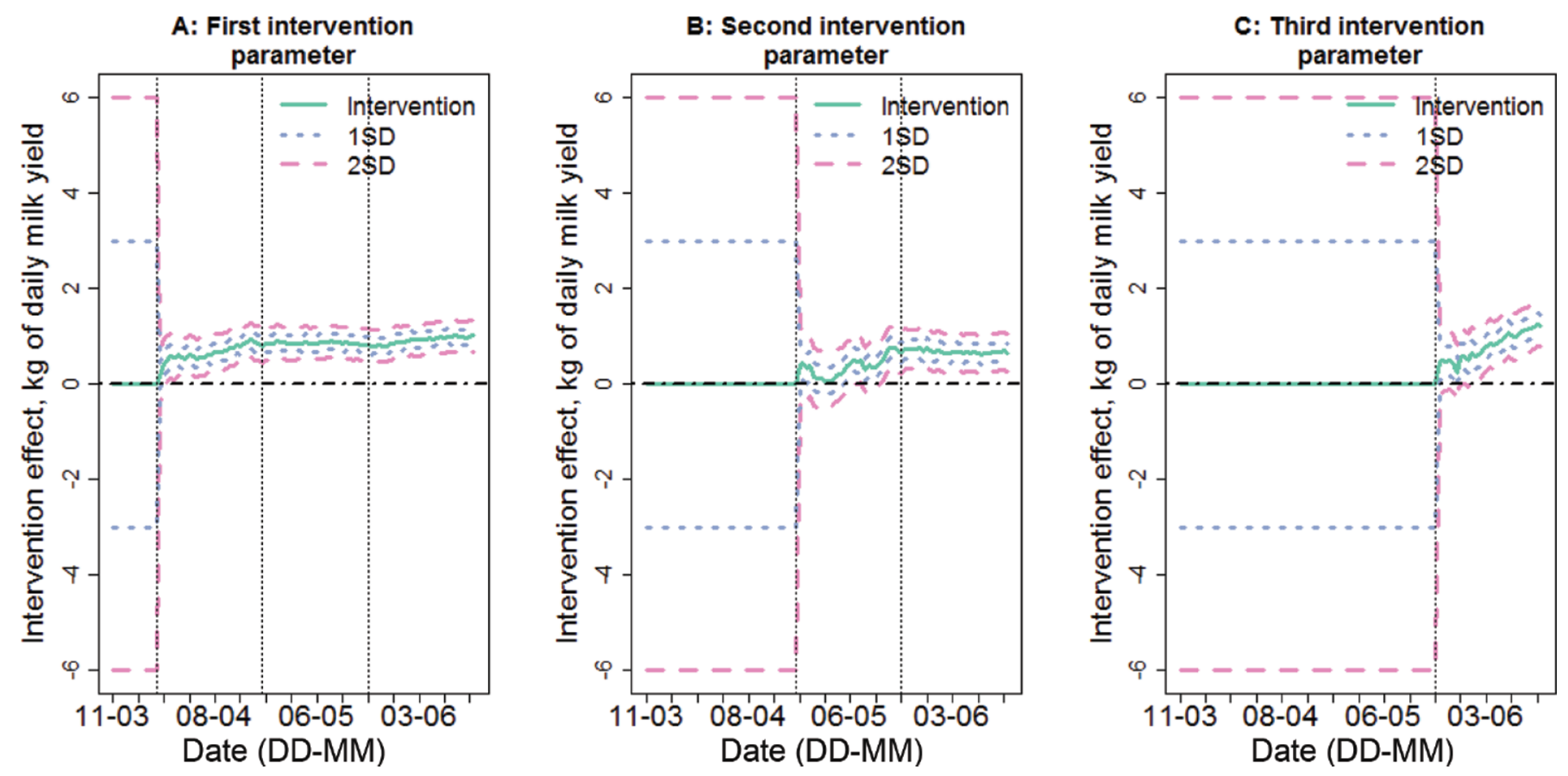

Figure 5. Intervention parameter (solid line) together with confidence intervals ( \pm SD dotted line and \pm 2 SD dashed line) for herd 1 with the (A) first reduction of energy provided through the automatic milking system (AMS), (B) second reduction of energy provided through the AMS, and $(\mathrm{C})$ third reduction of energy provided through the AMS. Dotted vertical lines mark the intervention dates. Color version available online. 
Based on these results, it was concluded that the changes in feeding strategy influence milk yield positively. In the examined herd, the proposed changes in feeding did not incur additional costs to the farmer (rather the opposite); thus, from an economic point of view, the herd manager of this particular herd should implement the proposed changes in concentrate supplementation for the whole herd.

The experimental design in herd 1 was a treatment and control group design. The role of the control group was to account for any environmental effects that could influence the obtained results. The effect of the control group could be easily tested by excluding milk yield data from cows in group 1 (Figure 6). The effect of intervention on milk production without the control group is less pronounced, and no significant positive or negative influence was detected. The inclusion of the control group affects the parameters representing the temporary environmental effects $X_{i j d}$ defined in Equation [3]. The results presented in Figure 6 might suggest that the second EVOP intervention in the herd 1 took place during a time of general decline for milk, which was reflected by the more positive response to the intervention seen when cows from the control group were included in the data used for model calculations.

\section{EVOP in Herd 2}

Values of intervention parameter (solid line) together with confidence intervals $( \pm$ SD dotted line and \pm 2 SD dashed line) for herd 2 were plotted on Figure 7. According to the results obtained from the DLM, the first change in energy concentration in the TMR had a statistically significant (at the $5 \%$ level) effect on milk production $2 \mathrm{~d}$ after the intervention start (Figure 7A). The second (Figure 7B) and third (Figure 7C) increase in energy concentration in TMR had no significant positive or negative effect on milk yield. The overall mean of all 3 intervention parameters after experiments was $2 \mathrm{~kg}$ (SD $0.34 \mathrm{~kg})$.

The constructed DLM model gives the possibility to look closer on cows in specific lactations (or even individuals). In the experiment conducted in herd 2, this particular ability of the tool was especially useful because the proposed intervention was expected to mainly affect primiparous cows. To evaluate the effect of intervention on cows in the first lactation only, data from test days were used (data from bulk tank were providing information on the herd level).

Results obtained for the first intervention (on March 10) for cows in lactation 1 (Figure 8A) revealed that the initial increase in energy concentration resulted in a significant increase in milk production. For the second and the third intervention (Figures $8 \mathrm{~B}$ and $8 \mathrm{C}$ ), no significant increase or decrease in milk production was observed. The overall mean of all 3 intervention parameters for cows in lactation 1 after experiments was 3.8 $\mathrm{kg}(\mathrm{SD} 0.6 \mathrm{~kg})$.

\section{DLM Versus Simple Statistics}

Benefits of DLM application can be seen when comparing obtained results with simple statistical calculations performed on the production data. The average ECM yield calculated based on the test-day milkings has been increasing for all 3 interventions in herd 2 . At the end of the experiment, the average ECM yield was approximately 2 and $3 \mathrm{~kg}$ higher for the whole herd (Figure 9A) and cows in lactation 1 (Figure 9B), respectively, compared with the situation before the experiments. However, by using such simple statistics it is not possible to identify to which degree the increase in milk yield was due to experimental changes and to which degree it was due to environmental effects or cow properties. For example, when taking into account only values for average production, a temporary increase in milk yield might be caused by the higher number of cows in the peak of lactation during that particular time.

Application of the multivariate DLM gives us the possibility to describe the lactation curves of all cows, to account for the influence of intervention, and to estimate the confidence intervals for parameters describing the intervention. The information about uncertainty of obtained results is indispensable for implementation of management strategies evaluated during experiments.

\section{Applicability of the Tool}

The presented DLM model together with functions used for loading production data and plotting the results was programmed in $\mathrm{R}$ and can serve as an on-farm optimization tool. The tool is designed to be used by advisers who would assist the farmer in designing and conducting EVOP interventions, running the model, and finally interpreting results.

Production results obtained on seemingly similar farms can vary a lot. Bach et al. (2008) studied the milk production on 47 dairy herds fed the same feed ration and sharing the same genetic base. Even though the studied farms were similar regarding feed management and genetics, they reported considerable variation (about $13 \mathrm{~kg} / \mathrm{d}$ ) in milk production among herds. The variation was due to nondietary factors (such as ap- 

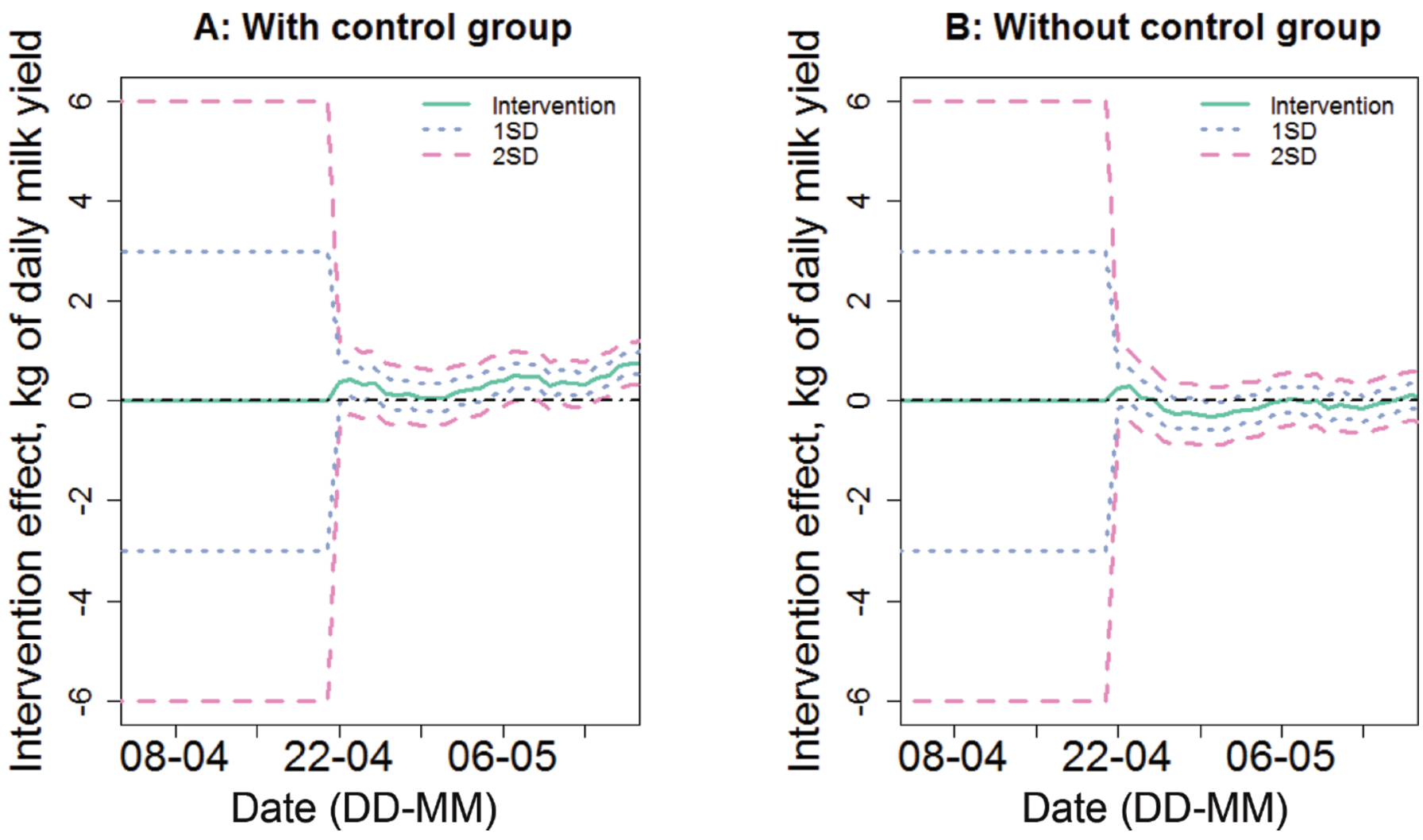

Figure 6. Influence of the control group on presented results, where (A) results are obtained when including the control group in model estimation, and (B) results are obtained without the control group. Presented are the example of second intervention parameter (solid line) together with confidence intervals $( \pm \mathrm{SD}$, dotted line and $\pm 2 \mathrm{SD}$, dashed line) for herd 1 . Color version available online.

plied rearing system of heifers, feed bunk management, and the number of cubicles available per lactating cow). For that reason, any potential changes to already applied strategies (e.g., changes in feeding management suggested by farm advisors) can bring different effects on similar dairy farms. Hence, in situations where precise predictions of intervention effects are needed to obtain high economic profit, any such modifications in herd management should be tested in the specific farm environment before being fully implemented.

With this study, we present a flexible tool which could be used for evaluating effects of systematic experimentation during the production process on milk yield. The tool can be used for supporting optimal production decisions during the standard production process in a local environment. However, the availability of production data is an obvious limiting factor for implementation of the tool on farms. As demonstrated with herd 2 (Figure 8), using only test-day milk records for cows in lactation 1 (gathered only twice per mo) reduced the precision of the estimates for intervention parameters. A similar tendency can also be noticed when decreasing the number of observed animals. As demonstrated by
Stygar et al. (2016), the number of observed cows (only one selected cow, 2 selected cows, or the whole robot group) influences the precision of the observed results. Therefore, to make decisions, a sufficient amount of observations regarding animals in the herd and their production process (including data on process variables such as for example energy concentration in a TMR) needs to be collected and integrated (e.g., test-day records with bulk tank records).

The presented model can be also used in farms with a limited production history. In those farms, DLM parameterization could benefit from test-day records collected from the whole country population.

The tool was developed to determine the effect of small changes in process variables, planned during systematic experimentation within the EVOP framework. However, the tool could be also used to monitor milk production during normal (non-EVOP) production flow. In the DLM intervention was modeled by adding the specific intervention parameter $\lambda$ to the equation describing milk yield (Equation [2]). Therefore, when using the tool during normal production flow simply parameter $\lambda$ would need to be 0 . 


\section{Perspectives}

To the extent of our knowledge, this is the first application of an EVOP design in dairy herds. The presented tool proved to be useful in evaluating the effects of interventions in 2 studied herds. The tool allows taking advantage of the increased amount of recorded data from the individual animal and thereby the tool provides a novel precision livestock farming technology that can help to support farmers in their management decisions. However, in the future some improvements of the model could be considered.

So far, in the model the effect of a control group was taken into account through an auto-correlated environmental effect. However, the model can be further improved by allowing environmental parameters $\left(X_{i j d}\right)$ to be correlated so that cow properties would be assumed to be mutually dependent. That would strengthen the potential effect of a control group. The value for correlation parameters could be obtained from regression analyses performed using the historical herd data.

Moreover, a potential improvement of the presented model could be achieved by allowing herd-specific parameters to evolve over time. To achieve this, the evolu- tion matrix for herd effect $\left(\mathbf{W}_{t}^{\phi}\right)$ would need to be estimated using the expectation-maximization algorithm.

The presented model estimated only the milk yield in response to an intervention. Milk yield is a key response when evaluating interventions in a dairy herd. However, other factors and performance parameters may be changed and should therefore also be evaluated. In the EVOP cases addressed in this study, this relates primarily to changes in feed costs, but could also include, for example, knock-on effects on health and fertility.

\section{CONCLUSIONS}

The multivariate DLM was applied for evaluation of the effects of systematic experimentation during the production process in 2 commercial Danish herds. For both experiments, the mean and standard deviation for parameters describing intervention were plotted and analyzed. The model was used for scenarios with different experimental designs and data sources. Values of intervention parameters can be easily obtained for specific times or specific animals (e.g., cows in a given lactation). Provided the amount of production data is
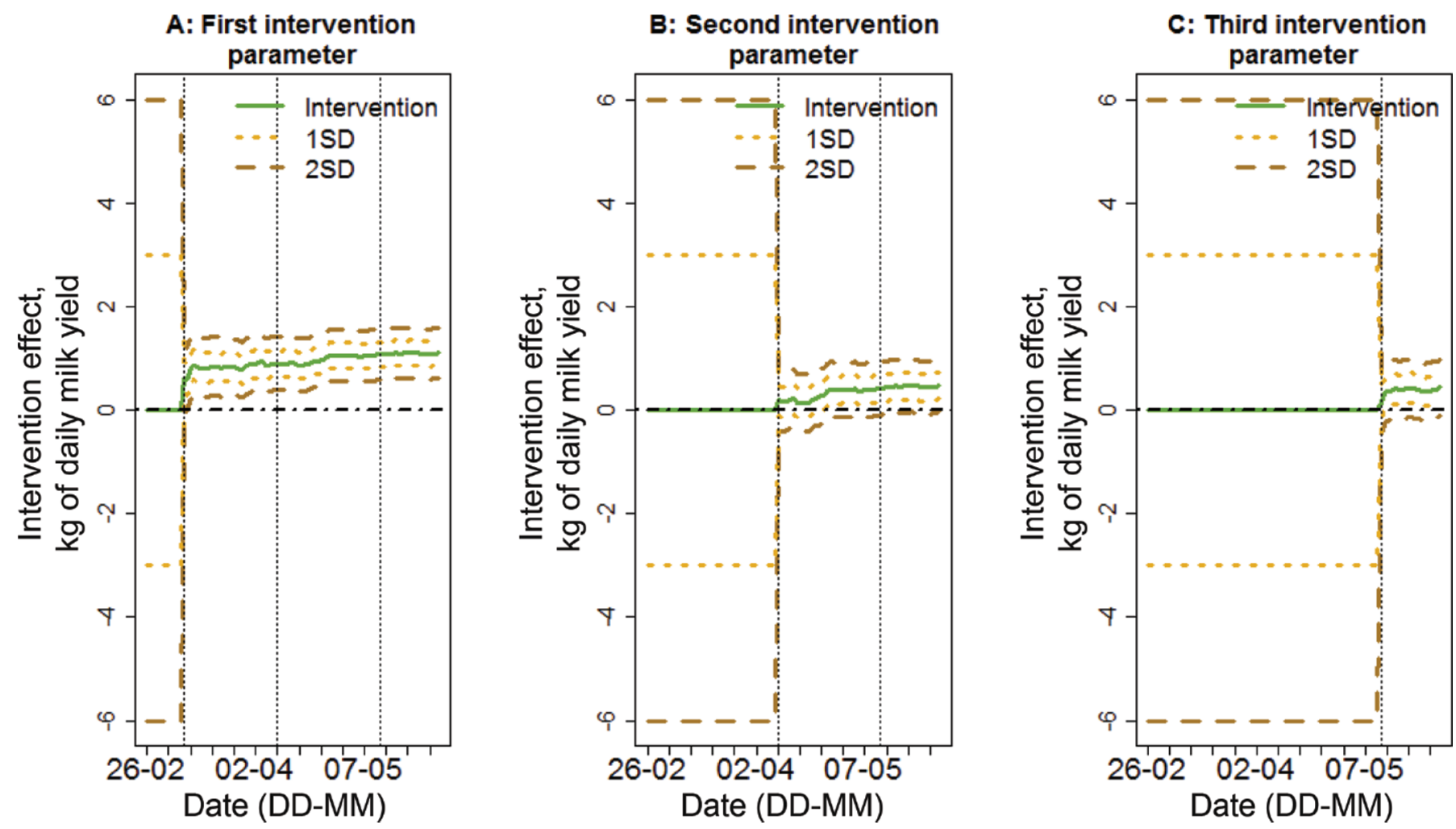

Figure 7. Intervention parameter (solid line) together with confidence intervals ( \pm SD dotted line and \pm 2 SD dashed line) for all cows in herd 2 with the (A) first increase in energy intake, (B) second increase in energy intake, and (C) third increase in energy intake. Color version available online. 


\section{A: First experimental challenge}

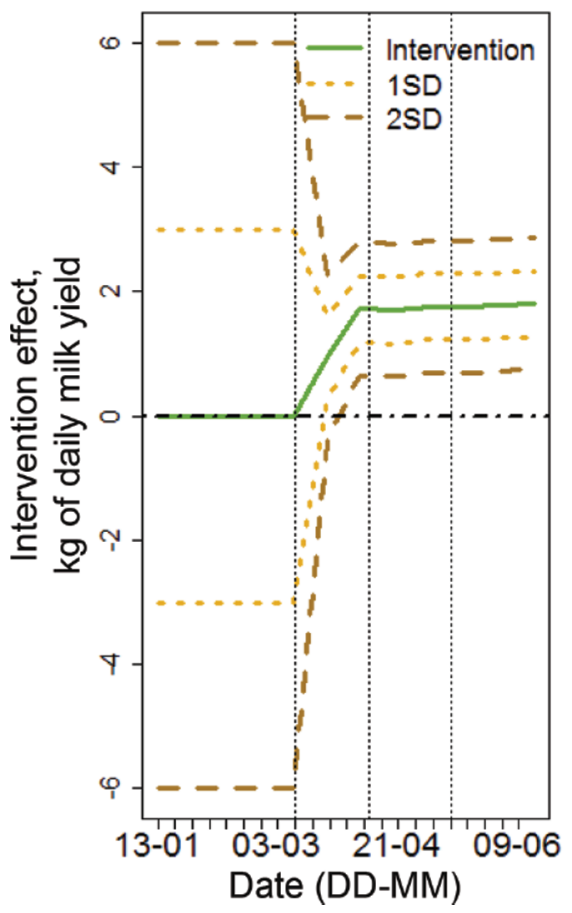

B: Second experimental challenge

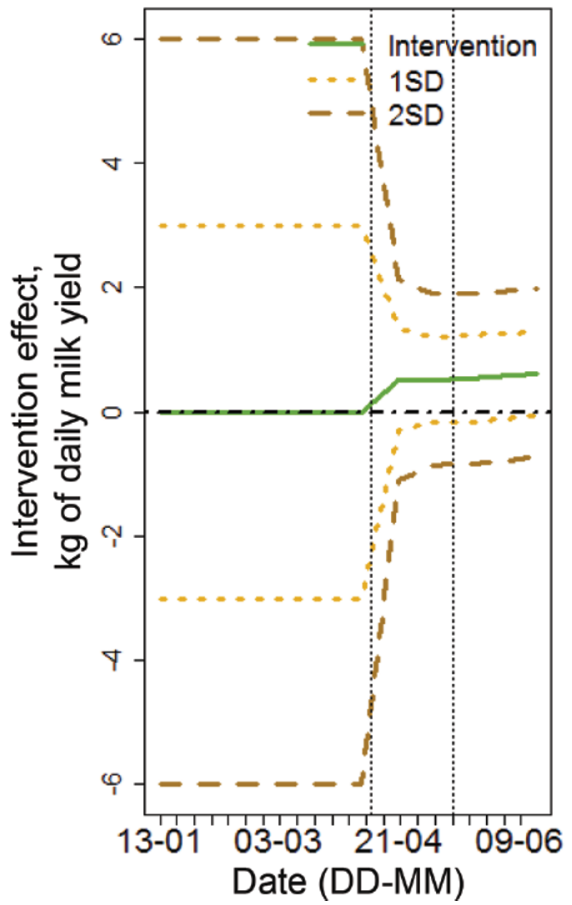

C: Third experimental challenge

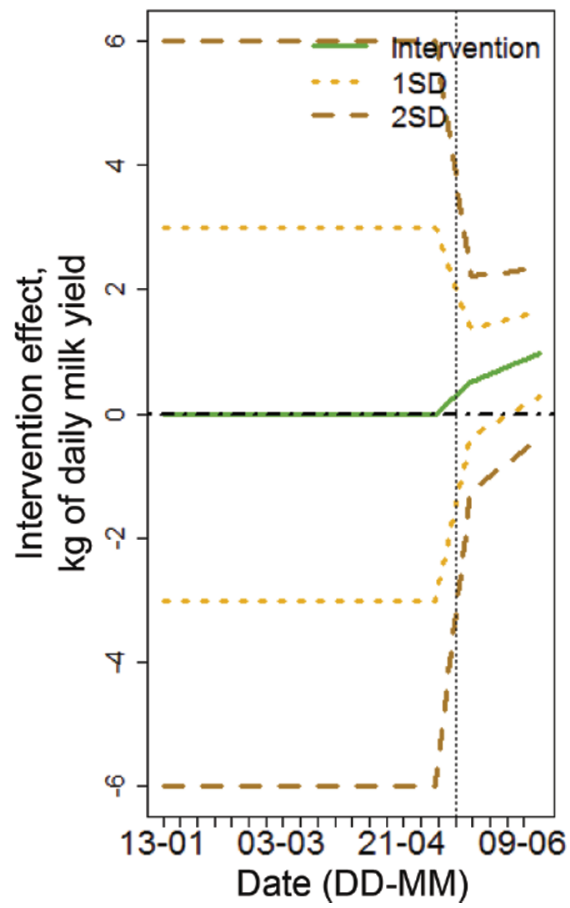

Figure 8. Intervention parameter (solid line) together with confidence intervals ( \pm SD dotted line and \pm 2 SD dashed line) for cows in lactation 1 , in herd 2 for all experiments. Color version available online.

A: Whole herd

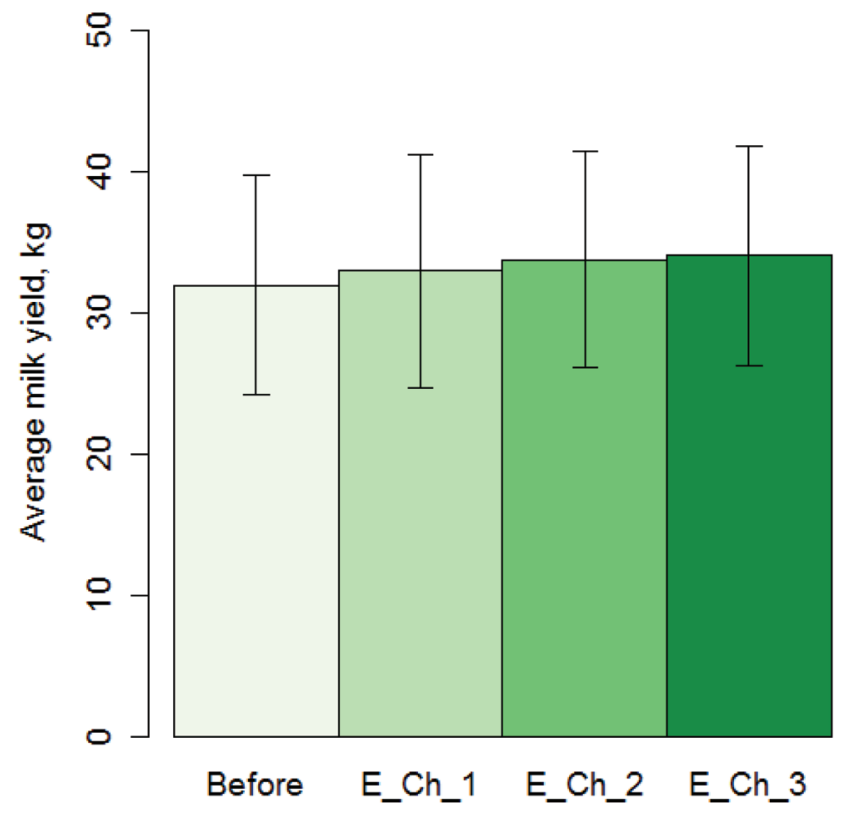

B: Cows in lactation 1

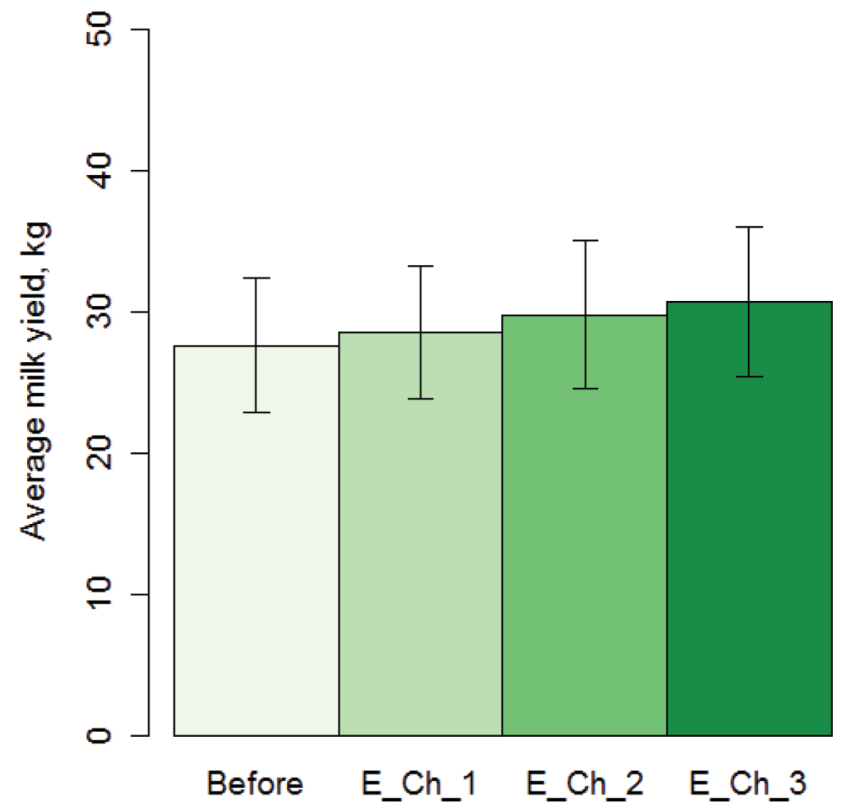

Figure 9. Average milk yield and standard deviation of milk yield calculated from records of test-day milkings for all cows in herd 2 (A) as well as for cows in lactation 1 (B), where "before" refers to the 1-mo period before intervention and E_Ch_1 to E_Ch_3 refer to periods with consecutive experimental interventions in the herd. Color version available online. 
sufficient, the tool can be used for supporting optimal production decisions in a local environment of a particular farm.

\section{ACKNOWLEDGMENTS}

This research was supported by the Milk Production Levy Fund (Aarhus) in Denmark and the Nordic Dairy Cattle R\&D. The authors thank the involved farmers.

\section{REFERENCES}

Andersen, H. M.-L., E. Jørgensen, and L. J. Pedersen. 2016. Using Evolutionary Operation technique to evaluate different management initiatives at herd level. Livest. Sci. 187:109-113. https://doi. org/10.1016/j.livsci.2016.03.006.

Bach, A., C. Iglesias, S. Calsamiglia, and M. Devant. 2007. Effect of amount of concentrate offered in automatic milking systems on milking frequency, feeding behavior, and milk production of dairy cattle consuming high amounts of corn silage. J. Dairy Sci. 90:5049-5055. https://doi.org/10.3168/jds.2007-0347.

Bach, A., N. Valls, A. Solans, and T. Torrent. 2008. Associations between nondietary factors and dairy herd performance. J. Dairy Sci. 91:3259-3267. https://doi.org/10.3168/jds.2008-1030.

Bennedsgaard, T. W., C. Enevoldsen, S. M. Thamsborg, and M. Vaarst. 2003. Effect of mastitis treatment and somatic cell counts on milk yield in Danish organic dairy cows. J. Dairy Sci. 86:31743183. https://doi.org/10.3168/jds.S0022-0302(03)73920-4.

Box, G. E. P. 1957. Evolutionary operation: A method for increasing industrial productivity. J. R. Stat. Soc. Ser. C Appl. Stat. 6:81-101. https://doi.org/10.2307/2985505.

Box, G. E. P., and N. R. Draper. 2006. Evolutionary Operation (EVOP). S. Kotz, C. B. Read, N. Balakrishnan, B. Vidakovic, and N. L. Johnson, ed. John Wiley \& Sons Inc., Hoboken, NJ.

Caccamo, M., R. F. Veerkamp, J. D. Ferguson, R. Petriglieri, F. La Terra, and G. Licitra. 2010. Associations of breed and feeding management with milk production curves at herd level using a random regression test-day model. J. Dairy Sci. 93:4986-4995. https://doi.org/10.3168/jds.2009-2835.

de Mol, R. M., A. Keen, G. H. Kroeze, and J. M. F. H. Achten. 1999 Description of a detection model for oestrus and diseases in dairy cattle based on time series analysis combined with a Kalman filter. Comput. Electron. Agric. 22:171-185. https://doi.org/10.1016/ S0168-1699(99)00016-2.

De Vries, A., and J. K. Reneau. 2010. Application of statistical process control charts to monitor changes in animal production systems. J. Anim. Sci. 88:E11-E24. https://doi.org/10.2527/jas.2009-2622.

Halachmi, I., E. Shoshani, R. Solomon, E. Maltz, and J. Miron. 2009. Feeding soyhulls to high-yielding dairy cows increased milk production, but not milking frequency, in an automatic milking system. J. Dairy Sci. 92:2317-2325. https://doi.org/10.3168/jds.2007-0958.

Jacobs, J. A., and J. M. Siegford. 2012. Invited review: The impact of automatic milking systems on dairy cow management, behavior, health, and welfare. J. Dairy Sci. 95:2227-2247. https://doi. org/10.3168/jds.2011-4943.

Jensen, D. B., H. Hogeveen, and A. De Vries. 2016. Bayesian integration of sensor information and a multivariate dynamic linear mod- el for prediction of dairy cow mastitis. J. Dairy Sci. 99:7344-7361. https://doi.org/10.3168/jds.2015-10060.

Jørgensen, C. H., A. R. Kristensen, S. Østergaard, and T. W. Bennedsgaard. 2016. Use of inline measures of l-lactate dehydrogenase for classification of posttreatment mammary Staphylococcus aureus infection status in dairy cows. J. Dairy Sci. 99:8375-8383. https:// doi.org/10.3168/jds.2016-10858.

Kristensen, A. R., L. Nielsen, and M. S. Nielsen. 2012. Optimal slaughter pig marketing with emphasis on information from online live weight assessment. Livest. Sci. 145:95-108. https://doi org/10.1016/j.livsci.2012.01.003.

Mayeres, P., J. Stoll, J. Bormann, R. Reents, and N. Gengler. 2004. Prediction of daily milk, fat, and protein production by a random regression test-day model. J. Dairy Sci. 87:1925-1933. https://doi. org/10.3168/jds.S0022-0302(04)73351-2.

Myers, R. H., and D. C. Montgomery. 1995. Response Surface Methodology: Process and Product Optimization Using Designed Experiments. Wiley, New York, NY.

Nielsen, L. R., E. Jørgensen, A. R. Kristensen, and S. Ostergaard. 2010. Optimal replacement policies for dairy cows based on daily yield measurements. J. Dairy Sci. 93:75-92. https://doi.org/10.3168/ jds.2009-2209

Pinheiro, J., D. Bates, S. DebRoy, D. Sarkar, and R Core Team. 2014. Nlme: Linear and Nonlinear Mixed Effects Models. R package version 3.1-131. Accessed Apr. 13, 2017 https://CRAN.R-project. org/package $=$ nlme

R Core Team. 2014. R: A Language and Environment for Statistical Computing. R Foundation for Statistical Computing, Vienna, Austria.

Sjaunja, L.O., B. Baevre, L. Junkkarinen, J. Pedersen, and J. Setala. 1990. A Nordic proposal for an energy corrected milk (ECM) formula. Pages 156-157 in Proc. 27th Session of International Committee for Recording Productivity of Milk Animals (ICRPMA) Eur. Assoc. Anim. Prod. Publ. No. 50 Eur. Assoc. Anim. Prod., Wageningen, the Netherlands.

Stygar, A. H., and A. R. Kristensen. 2016. Monitoring growth in finishers by weighing selected groups of pigs - A dynamic approach. J. Anim. Sci. https://doi.org/10.2527/jas.2015-9977.

Stygar, A. H., M. A. Krogh, S. Østergaard, and A. R. Kristensen. 2016. Tool for assessing the intervention effect on milk production in an evolutionary operation setup. Pages 233-237 in Precision Dairy Farming 2016. Wageningen Academic Publishers, Wageningen, the Netherlands.

Thysen, I. 1993. Monitoring bulk tank somatic cell counts by a multiprocess Kalman filter. Acta Agric. Scand. A Anim. Sci. 43:58-64. https://doi.org/10.1080/09064709309410145.

Toft, N., and E. Jørgensen. 2002. Estimation of farm specific parameters in a longitudinal model for litter size with variance components and random dropout. Livest. Prod. Sci. 77:175-185. https:// doi.org/10.1016/S0301-6226(02)00061-1.

Van Bebber, J., N. Reinsch, W. Junge, and E. Kalm. 1999. Monitoring daily milk yields with a recursive test day repeatability model (Kalman filter). J. Dairy Sci. 82:2421-2429. https://doi. org/10.3168/jds.S0022-0302(99)75493-7.

Volden, H. 2011. NorFor-The Nordic Feed Evaluation System. Wageningen Academic Publishers, Wageningen, the Netherlands.

West, M., and J. Harrison. 1997. Bayesian Forecasting and Dynamic Models. 2nd ed. Springer-Verlag, New York, NY. 